\title{
THEORETICAL JUSTIFICATION FOR THE ESTABLISHMENT OF THE CENTER FOR SOCIAL REHABILITATION AND INTEGRATION
}

\author{
Ivelina Dimitrova \\ National Sports Academy "Vassil Levski", Sofia, Bulgaria
}

\begin{abstract}
The current study aims to analyze the information on the establishment of the Center for Social Rehabilitation and Integration (CSRI) as a tool for providing social service, integration, and opportunities in improving the quality of life in the community for people with disabilities. Based on the above, strategies and practices around the world on the regulation of standards and the classification, diagnosis and assessment of impairments, health conditions and level of functioning were theoretically examined and analyzed. Additionally, it analyzes the practices in Bulgaria regarding the policy, legal and regulatory frameworks and their implementation as well as the regulation of standards regarding the qualification and competencies of specialists working with people with disabilities.

For this study, a survey was conducted to identify the priorities and motivation of people with disabilities attending the CSRI on the one hand, and those of professionals working with them on the other. Respondents were 45 patients, attending the Sofia Municipal Day Care Center for Social Integration of Persons with Disabilities - Slatina and the Medical Center for Children with Developmental Disabilities - Student City. Other group respondents were 30 experts from CSRI - Slatina - rehabilitators, kinesitherapists, ergo-therapists, psychologists, speech therapists, pedagogues, social workers, occupational therapists, family therapists and doctor of different age, age (from 23 to 65 years), the educational degree was also interviewed.

One-dimensional and two-dimensional frequency distributions were made by processing the data and inserting them into a statistical analysis program.

The CSRI has an extremely important role in the care and adaptation of people with disabilities to the community, but the system for assessing disability is stimulating institutionalization, not socialization. If the assessment methodologies are updated and the attitudes and priorities in the work with people with disabilities are synchronized and adapted to the activities of daily living - improving the quality of social service, the quality of life of people with disabilities will be improved.
\end{abstract}

Key words: social integration, impairment, classification, disabilities

\section{INTRODUCTION}

Disability or impairment is a state of limitation of an individual to interact with the environment, which creates physical, social, moral and even intellectual disabilities. According to statistics in most countries, every 1 in 10 people suffer from some kind of disability and this affects $25 \%$ of the population. The main causes of disability are: wars and natural disasters, earthquakes, terrorism, environmental pollution, epidemics, starvation and illiteracy, neglect of disease processes, remoteness and lack of access to timely medical care, occupational accidents, work-related accidents transport incidents, drug and drug use, increasing urbanization and population growth, excessive stress and psycho-social problems, and etc. (Eurostat, 2012) In 2002, Geneva published a classification answering definitely those problems - "Internation- al Classification of Functioning, Disability and Health" - ICF (International Classification of functioning, disability and health), which, the same ICD10, belongs to the family of international classifications. This is a classification for human health and related areas that help us describe changes in the functioning and structure of the body, describe what a person with a health problem can do in their daily environment -level of opportunity, and what which actually makes the person in their normal environment -level of performance. (Sokolowska, Holowska \& Ostrowska, 1978)

The process of development of the International Classification of Diseases, Disorders and Causes of Death (ICD 10-ICD) and the International Classification of Diseases, Disability and Health (ICF) is a sort of pathway that shows the evolution of world- 
wide views in the scientific world. the models for examining this medico-social phenomenon - disability. (World Health Organization, 2002)

According to National Statistical Institute data (2016) people with disabilities of working age (over 16 years) for 2015 they number 68887 people or $11.1 \%$ of the total working-age population. The persons with over $90 \%$ permanently reduced working capacity are $23.2 \%$ of them, those between 71 $90 \%$ reduced working capacity are $32.9 \%, 50-70 \%$ reduced working capacity $-32.2 \%$ and those with up to $50 \%$ reduced working capacity are $11.7 \%$. $40.5 \%$ of all persons with disabilities have an existence of the disability and only almost $37.0 \%$ have a term of 2-3 years. The most common reason for placing a person in the group with disabilities are diseases of the circulatory organs, followed by neoplasms, diseases of the musculoskeletal and connective tissue, diseases of the endocrine system, eating disorders and metabolism, etc. (Nationalen Statisticheski Institute, 2016)

Persons with permanent disabilities have the right to medical and social rehabilitation.

Medical rehabilitation is a medical activity carried out by multidisciplinary teams under the terms and procedures of the Medical Establishments Act and the Health Insurance Act, which includes: maintenance drug therapy; physical therapy; speech and vision therapy; kinesitherapy; ergotherapy; psychotherapy; occupational treatment; appointment of aids, devices and equipment and medical devices for the disabled.

Social rehabilitation is the creation of skills to lead an independent life through the rehabilitation of vision, hearing and speech, motor rehabilitation, psychological assistance, provision of social services and other activities.

"The Center for Social Rehabilitation and Integration" is a complex of social services for persons related to rehabilitation, social-legal counselling, educational and vocational training and guidance, preparation and implementation of individual programs for social inclusion. (Darjaven vestnik, 2004)

\section{METHODOLOGY}

The objective of this study was to analyze The Centre for Social Rehabilitation and Integration as an instrument for providing social service in the community for people with disabilities, its functions and opportunities for improving the quality of life of this group of people.

\section{Tasks:}

- Using the method of the questionnaire and statistical evaluation to consider and analyze the opinion, motivation and priorities of people with disabilities and specialists working with them.

- Analysis and comparison of activities in different centers.

- Showing the requirement for appropriate qualification of specialists working with people with disabilities and continuing education.

The subject of the study was 45 patients and 30 specialist who work with them.

The methods for current survey, we used two types of questionnaires: a type for professionals working with people with disabilities, which includes general questions, such as those related to career guidance and experience, motivating factors in work, opinion on service delivery, and level of engagement and a type of survey for people with disabilities that includes general questions about the service, motivation and needs when visiting the center.

A respondent's group was 45 people attending the CSRI- Slatina (34 patients) and the Medical Center for Children with Developmental Disabilities (MCCDD) - Student City (11 patients). The first center is part of the Agency for Social Support system for providing social service in the community and provides free service (only for persons over 18 years. a fee is set in a symbolic amount - up to $5 \%$ of the declared income), and the second center is medical and private - the service is paid there. The distribution by age, gender, place of use of social/medical rehabilitation and services, limitation of the disability, employment and /no/ dependency are made based on the methods of descriptive statistics and are presented in tabular form (Table 1). 
Table 1. Respondents - people with disabilities

\begin{tabular}{|c|l|ll|}
\hline Question № & \multicolumn{1}{|c|}{ Participant profile } & Number of participants & \% \\
\hline \multirow{2}{*}{2} & Male & 26 & 57,8 \\
& Female & 17 & 37,8 \\
& Missing dates & 2 & 4,4 \\
\hline \multirow{2}{*}{$\mathbf{1}$} & under 18г. & 19 & 42,2 \\
& over18г. & 26 & 57,8 \\
\hline \multirow{2}{*}{$\mathbf{4}$} & Not assistant & 11 & 24,4 \\
& With assistant & 34 & 75,6 \\
\hline \multirow{2}{*}{$\mathbf{5}$} & Not working & 39 & 86,7 \\
& Working & 6 & 13,3 \\
\hline
\end{tabular}

\section{RESULTS}

The two-dimensional distribution shows that for the respondents from the CSRI, the majority of them visit it for more than five years, and the lowest is the percentage of visitors less than a year, while in the MCCDD the percentage is opposite and it is shown in the Figure 1.

\section{Term of using services of centre CSRI/MCCDD}

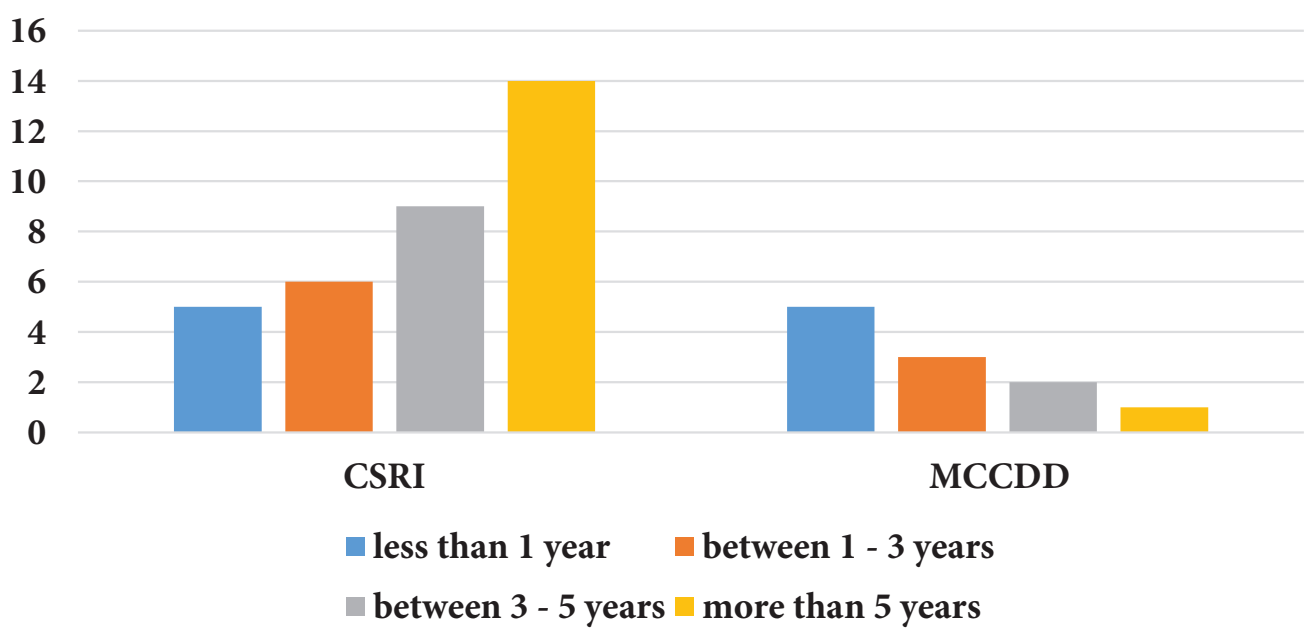

Figure 1. Term of using services of center CSRI/MCCDD

It should also be noted for persons over 18 that 14 rehabilitators, kinesitherapists, ergotherapists, psyof them $(77.8 \%)$ are unemployed and the remain- chologists, speech therapists, pedagogues, social ing only 4 persons (22.2\%) are employed (Table 2) workers, occupational therapists, family therapist and doctor with different experience, age /from

Other group was 30 specialists were interviewed 23 to 65 years/, educational degree. The frequency by questionary, employees of CSRI - Slatina (20 analysis of the sample data was presented visually people) and MCCDD - Student city (10 people): in the relevant tables - No 3. 
Table 2. Respondents - disabled people, age, employment

\begin{tabular}{|c|c|c|c|c|c|}
\hline \multicolumn{6}{|c|}{ age / employment two-dimensional distribution } \\
\hline & & & \multicolumn{2}{|c|}{ Employment } & \multirow{2}{*}{ total } \\
\hline & & & not working & working & \\
\hline \multirow{6}{*}{$\underset{\sigma}{\mathbb{E}}$} & \multirow{3}{*}{$\begin{array}{l}\infty \\
\stackrel{\infty}{0} \\
\vdots \\
0\end{array}$} & Number of participants of & 14 & 4 & 18 \\
\hline & & $\%$ by age & $77,8 \%$ & $22,2 \%$ & $100,0 \%$ \\
\hline & & $\%$ by employment & $35,9 \%$ & $66,7 \%$ & $40,0 \%$ \\
\hline & \multirow{3}{*}{$\begin{array}{l}\frac{\infty}{2} \\
\frac{0}{0} \\
\frac{0}{0}\end{array}$} & Number of participants & 25 & 2 & 27 \\
\hline & & $\%$ by age & $92,6 \%$ & $7,4 \%$ & $100,0 \%$ \\
\hline & & $\%$ by employment & $64,1 \%$ & $33,3 \%$ & $60,0 \%$ \\
\hline \multirow{3}{*}{\multicolumn{2}{|c|}{ હَّ }} & Number of participants & 39 & 6 & 45 \\
\hline & & $\%$ by age & $86,7 \%$ & $13,3 \%$ & $100,0 \%$ \\
\hline & & $\%$ by employment & $100,0 \%$ & $100,0 \%$ & $100,0 \%$ \\
\hline
\end{tabular}

Table 3. Respondents specialists

\begin{tabular}{|l|l|l|l|}
\hline \multicolumn{1}{|c|}{ Specialization } & \multicolumn{1}{c|}{ Questions } & $\begin{array}{c}\text { Number of } \\
\text { participants }\end{array}$ & \multicolumn{1}{c|}{$\%$} \\
\hline rehabilitator & specialty & 5 & 16,7 \\
\hline kinesitherapist & specialty & 8 & 26,7 \\
\hline psychologist & specialty & 3 & 10,0 \\
\hline speech therapist & specialty & 3 & 10,0 \\
\hline special pedagogue & specialty & 2 & 6,7 \\
\hline social worker & specialty & 4 & 13,3 \\
\hline family therapis & specialty & 1 & 3,3 \\
\hline doctor & specialty & 1 & 3,3 \\
\hline occupational therapists & specialty & 2 & 6,7 \\
\hline pedagogue & specialty & 1 & 3,3 \\
\hline professional bachelor & educational level & 4 & 13,3 \\
\hline bachelor & educational level & 6 & 20 \\
\hline master & educational level & 18 & 60 \\
\hline doctor & educational level & 2 & 6,7 \\
\hline Less than 1 year & work experience & 6 & 20 \\
\hline $1-3$ years & work experience & 4 & 13,3 \\
\hline $3-5$ years & work experience & 4 & 13,3 \\
\hline More than 5 years & work experience & 16 & 53,3 \\
\hline
\end{tabular}

\section{DISCUSSION}

Attention of in the results of this survey are both the analysis of the motivating factors and the opinion of specialists about some changes in the provision of social service in the community, as well as the subjective estimation of the unsatisfactory results in work and the interrelationship of this with work experience, age, specialty or educational degree. In the group of persons over 18 years. the use of specialists and services outside the CSRI - Slatina is in $50 \%$ of the cases. The most used service is again medical / motor rehabilitation, and obviously, the representatives of the age group under 18 are more active in demand for therapeutic alternatives.

Overall, the respondents show a remarkably common high level of satisfaction with the indicators related to the sufficiency of the service/satisfaction of the individual need /, subjective assessment for improving the condition and quality of life.

An interesting regularity distribution is formed, which is not typical but is a fact in this case - grouping the majority of answers in the final possible 
positions - strongly „Yes” and strongly “No” (Figure 2)

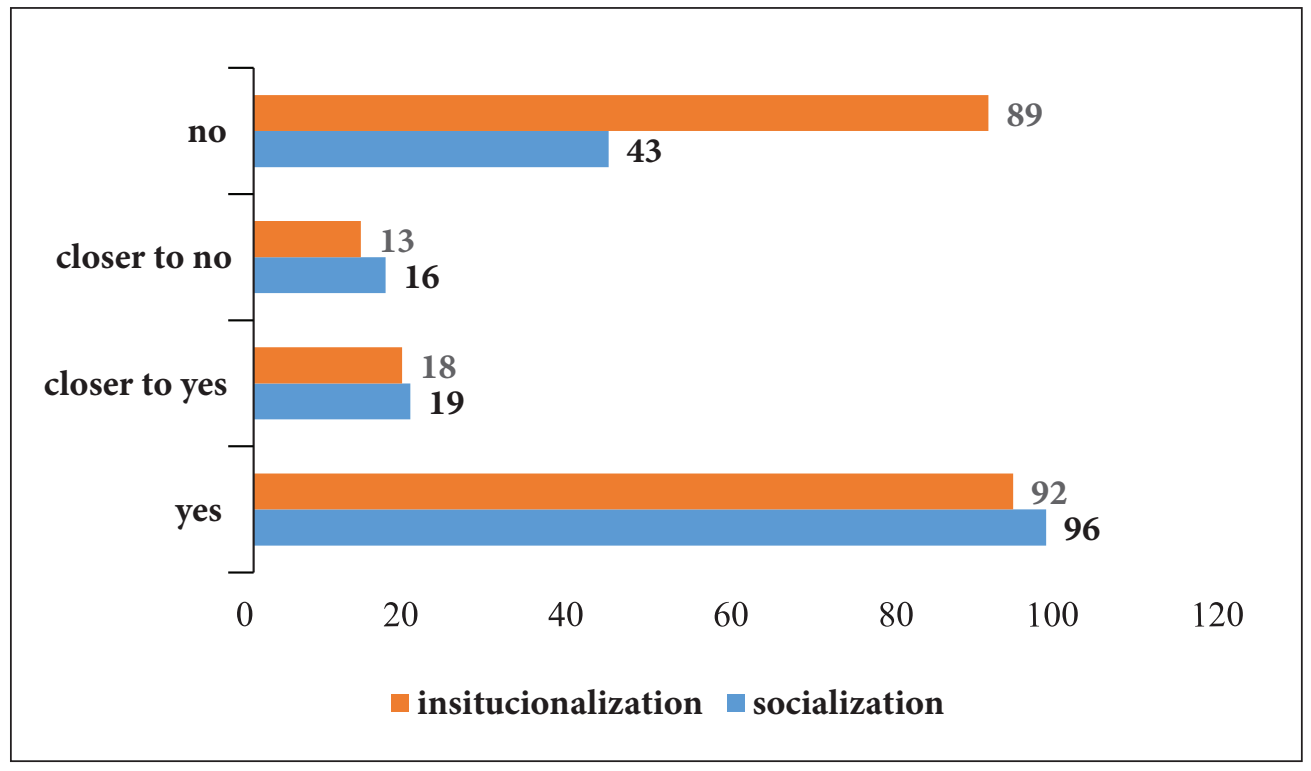

Figure 2. Socialization and Institutionalization answer results

In processing the data from the questionnaire for specialists, the interest and attention were directed to the subjective assessment of the nature of the work (presence or lack of results, difficulties, the feeling of unpreparedness), failure and motivation.

When comparing data by specialty, we divided the surveyed experts into three groups. Health professionals in two groups

- rehabilitators (group 1) on the one hand and kinesitherapists, ergo therapists and doctors on the other (group 2)/, and other specialists

- with a more socially-pedagogically oriented profile in the third group - others. The result is shown in Figure 3.

There is a slight tendency of decrease in "professional self-esteem" from group 1, through group 2 and, accordingly, the lowest self-esteem in group 3. of the client/patient is the largest. In the other two groups, the criticality towards oneself and the client/patient is increasing, however, the specialists with a socio-pedagogical profile turn out to be the most critical to their abilities and efforts, while the kinesitherapists and doctors are the most critical to the client/patient. Consequently, a small difference in these indicators was observed in the third group.

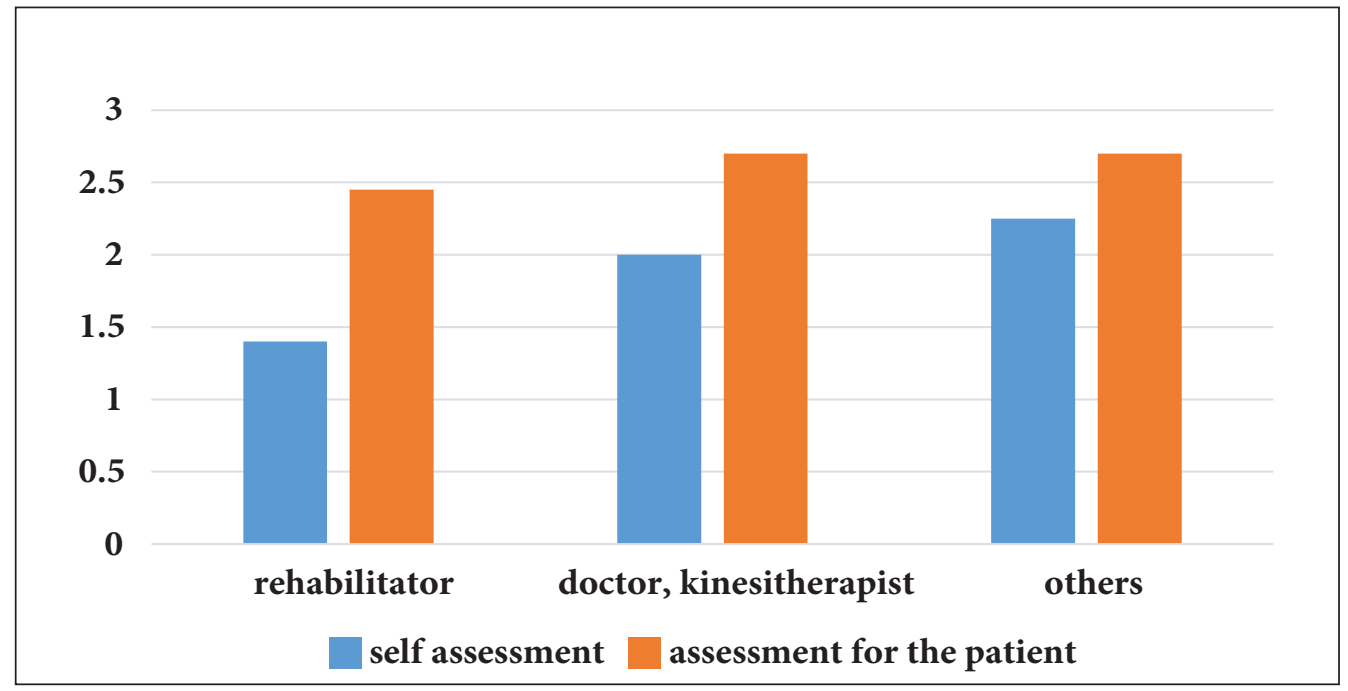

Figure 3. Comparing data by specialty 
The comparison of majors in assessing the significance of the relevant motivating factors for the questioned persons is presented in Figure 4.

It can be said that there is a tendency to decrease the importance of commercial factors in the three groups - it is most pronounced in the first group (rehabilitators), less pronounced in the second group (kinesitherapists and doctors) and the least importance is given to the representatives of group 3 - socio-pedagogical profile. In determining moral and ethical factors, however, the results are almost equal, with the second and third groups being the most highly rated and the first group being less rated as motivating.

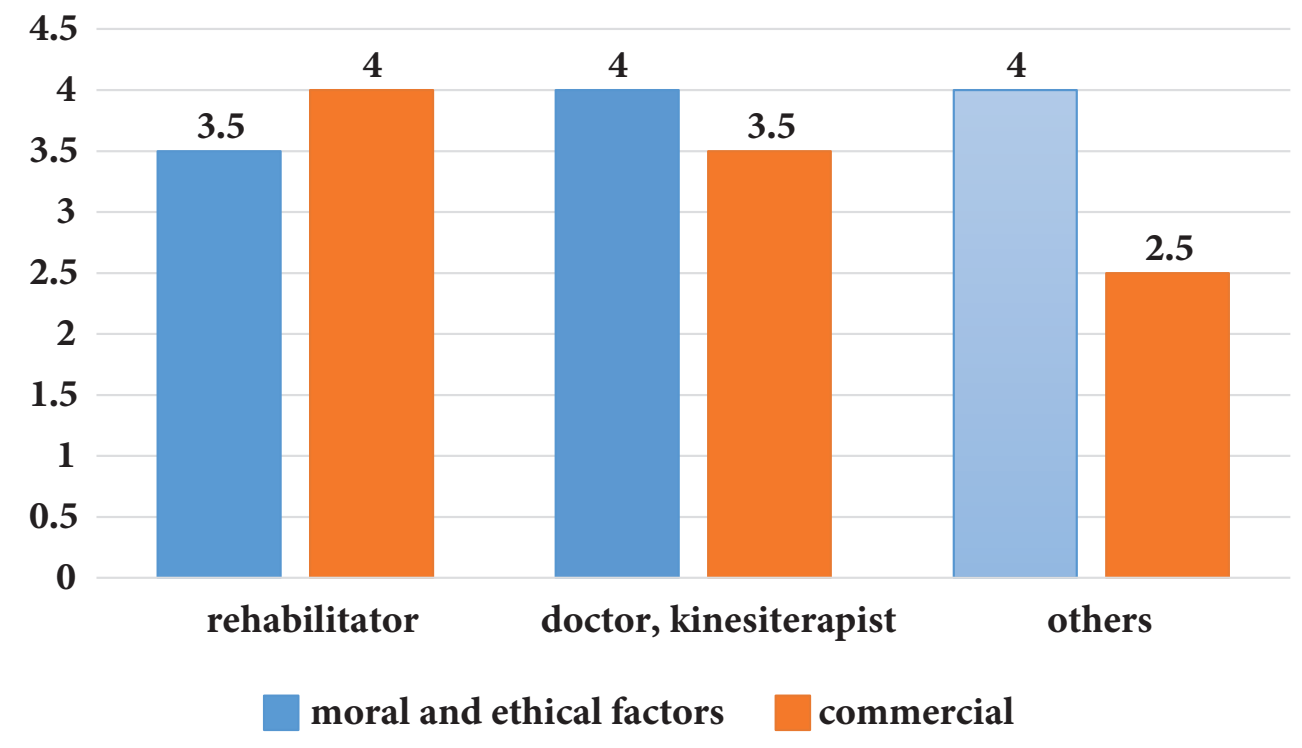

Figure 4. Comparing of the relevant motivating factors

The following conclusions can be extracted from the present work:

The way of determining the level of incapacity for work in the Republic of Bulgaria stimulates the disabled to consumer attitude towards the measures and services provided by the state institutions.

The CSRI has the potential to play a supporting role in the socialization of people with disabilities. The applying process for using social service in the community is cumbersome and prevents active, integrated individuals from enjoying the opportunities to improve their quality of life.

Medical/motor rehabilitation is leading/ preferred in the range of services provided by the services centers.

In general (with few exceptions) people with disabilities give a very high level of satisfaction with the services they use and the professionals who work with them regardless of the center or the period of use of its services.

Persons with disabilities present little to a moderate level of wish for a change in terms of service delivery and quality.
There is a tendency towards institutionalization (Consumer attitudes when using social services) People with disabilities tend to "shut down" in their communities where they feel more relaxed and welcomed than among the community they perceive as unfriendly or even hateful.

Specialists working with people with disabilities express satisfactory gratitude for their professional success, and in the absence of such, tend to attribute the condition and activity to the client/patient rather than their capabilities and competencies.

Workers in this field give a very high level of orientation towards moral and ethical motivating factors in their work towards material ones.

Based on the conclusions extracted, the following recommendations can be made:

Establish exact criteria for the competences, qualifications, status and field of work of professionals involved in improving the quality of life of people with disabilities and introduce communication standards for them for integration purposes/reintegration of the disabled person.

Put into practice the evaluation of ICF functions 
to determine first of all the quality of life of people with disabilities and, last but not least, the importance of focusing on their functions, and their inclusion in society.

Specialists should be trained in internationally approved skills development concepts and exchanged between units of identical function.

"Health is a state of complete physical, mental and social well-being" which is just one of the many definitions of this extremely complex and comprehensive category. (World Health Organization, 1980) The social system, with its sub-categories economic, social, environmental and cultural - appears to be a serious factor for a healthy and harmonious life. Permanent disability brings with it not only health problems from a medical point of view, but also problems related to the inability to work, develop, and in some cases, to complete disengagement from society, which from its end covers the way for psychological changes in the individual.

\section{REFERENCES}

Darjaven vestnik. (2004). Zakon za integraciata na horata s uvrejdania.17 September, pp.81 // Държавен вестник
(2004) Закон за интеграция на хората с увреждания. 17 Септември, стр.81

Eurostat. (2012). Labour Force Survey (LFS) ad-hoc module on employment of disabled people, Doc 2012-PH-06, European Commission, Luxembourg, 25-26 September Nationalen Statisticheski Institute. (2016). Zdraveopazvane 2015, 19 January, pp.9 // Национален Статистически Институт (2016), Здравеопазване 2015, 19 Януари, стр.9

Sokolowska, M., Holowska, J. and Ostrowska, A. (1978). Health, Medicine, Society. Psychological Medicine, 8(2), pp.352-352.

World Health Organization (1980). International classification of impairments, disabilities and handicap, WHA29.35, World Health Organaization, Geneva 1980, pp. 25-47

World Health Organization (2002). International classification of functioning, disability and health: ICF, World Health Organization, Geneva, pp. 45-171

Corresponding author: Ivelina Dimitrova, National Sports Academy "Vassil Levski" 21, Acad. Stefan Mladenov, str. E-mail: Dimitrova.nsa@gmail.com 